\title{
Trialing net illumination as a bycatch mitigation measure for sea turtles in a small-scale gillnet fishery in Ecuador
}

\author{
Jodie J. Darquea ${ }^{1,2}$, Clara Ortiz-Alvarez ${ }^{3}$, Francisco Córdova-Zavaleta ${ }^{3}$, Robert Medina ${ }^{1}$ \\ Alessandra Bielli ${ }^{3}$, Joanna Alfaro-Shigueto ${ }^{3,4,5}$ \& Jeffrey C. Mangel $^{3,5}$ \\ ${ }^{1}$ Ecuador Mundo Ecológico, Salinas, Ecuador \\ ${ }^{2}$ Universidad Estatal Península de Santa Elena, La Libertad, Ecuador \\ ${ }^{3}$ Pro Delphinus, Lima, Perú \\ ${ }^{4}$ Facultad de Biología Marina, Universidad Científica del Sur, VES, Lima, Perú \\ ${ }^{5}$ Marine Turtle Research Group, Centre for Ecology and Conservation, University of Exeter \\ Campus Penryn, Cornwall, United Kingdom \\ Corresponding author: Joanna Alfaro-Shigueto (jalfaros@ ucientifica.edu.pe)
}

\begin{abstract}
In Ecuador, one of the main hazards for threatened marine species, such as sea turtles, is smallscale fisheries bycatch. At a global scale, currently, bycatch reduction technologies (BRTs) are being tested in many coastal nations to mitigate this issue. Despite some advances in Ecuadorian efforts for wildlife protection, BRTs to reduce bycatch have yet to be assessed. The purpose of this study was to test the BRT of net illumination using violet light-emitting diodes (LEDs) as a mitigation measure to reduce sea turtle interactions in the smallscale driftnet fishery operating from the ports of Santa Rosa, Puerto Lopez and Jaramijo. A total of 146 pairs of experimental sets (control and illuminated panes) were deployed in all ports. A generalized linear mixed-effect model (GLMM) was employed to analyze the bycatch per unit of effort (BPUE) for sea turtles, and the catch per unit of effort (CPUE) for target species; for both control and illuminated panes. Thirty-two sea turtles from three species were observed captured: olive ridley Lepidochelys olivacea $(n=18)$, green Chelonia mydas $(n=13)$ and leatherback turtles Dermochelys coriacea $(n=1)$. Turtle species-specific modeling showed bycatch of green turtles declined by $93 \%$ in illuminated nets compared with control, non-illuminated nets, whereas no significant difference between control and illuminated nets was observed for olive ridley turtles. The catch per unit effort of the pelagic fish species including skipjack tuna, yellowfin tuna, mahi-mahi, thresher shark and smooth hammerhead shark was not affected by net illumination. Our results represent the first evaluation of the effects of net illumination using LEDs on reducing marine turtle bycatch in Ecuadorian small-scale driftnet fisheries. Despite its relatively small sample size, these results could be used by fisheries managers to support the implementation or further testing of this BRT in gillnet fisheries along the Ecuadorian coast.
\end{abstract}

Keywords: LEDs; sea turtles; small-scale fishery; bycatch; mitigation; Ecuador

\section{INTRODUCTION}

Ecuador possesses one of the largest small-scale fisheries (SSF) fleets of the countries of the Eastern Pacific Ocean (EPO) (Alava et al., 2015). Ecuadorian SSF is multispecies and employs mainly longlines and gillnets, with landings representing 19\% of total annual national catch (Alava et al., 2015; Martínez-Ortiz et al., 2015). It is estimated that over 5\% of the economically active population depends on this activity (Alava et al.,
2019). During the 1990s, the Ecuadorian small-scale fishing fleet doubled in size from 7,000 to 15,500 vessels (Alava et al., 2019). Fishing activity has also increased and extended further offshore with the adoption of a "mother ship" fleet. These vessels, which tow up to 10 smaller fiberglass vessels, are capable of traveling far offshore (even to Galapagos Island [Alava et al., 2015]) and allow up to 25 days at sea before returning to the shore (Martínez-Ortiz et al., 2015). The 2013 Ecuador census recorded 21,798 operative artisa-

Corresponding editor: Patricio Arana 
nal vessels, of which 317 corresponded to "mother ships". The expansion of the sector along the continental coastline and the Galapagos Archipelago could also increase the likelihood of overlapping with areas of marine megafauna occupancy such as marine mammals, sea turtles, seabirds and elasmobranchs.

The concern over fisheries bycatch arises from a combination of vulnerability due to ecological attributes of the species affected and of susceptibility to interactions driven by fishing characteristics (Lewison et al., 2014). For example, marine megafauna populations are vulnerable to relatively low level of bycatch due to life history characteristics (e.g., slow growth, low reproductive rates) and also susceptible to excessive incidental mortality caused by fisheries (Heppell et al., 2000; Lewison et al., 2004); this has been highlighted in numerous studies focusing on seabirds, sea turtles, marine mammals, and elasmobranchs (Mangel et al., 2010; Anderson et al., 2011; Attwood et al., 2011). Despite bycatch being identified as a primary threat and driver of many marine megafauna population declines (Wallace et al., 2010; Lewison et al., 2014) and other non-target species difficult to assess (Kelleher, 2005), its cumulative effects are often underestimated by some fishers since they are caught sporadically and represent only a small part of the total bycatch biomass (Soykan et al., 2008).

In Ecuador, five species of sea turtles use coastal areas for nesting, migration and foraging (MAE, 2014). The Galapagos Islands holds one of the most important nesting sites of green turtles (Chelonia mydas) along the EPO, with more than 1309 nests identified from 2004 to 2007 (Zárate et al., 2013). Results from Chaves et al. (2017) also indicate genetic connectivity between the Galapagos population of green turtles with nesting sites at the Machalilla National Park on the Ecuador mainland (Peña-Mosquera et al., 2009). Ecuador rookeries of olive ridley turtles (Lepidochelys olivacea) and hawksbill turtles (Eretmochelys imbricata) have also been identified (Montero et al., 2016; Gaos et al., 2017). Two majors threats for sea turtles populations in the southeastern Pacific include plastic debris ingestion (Thiel et al. 2018) and fisheries interactions, with nets and longlines in particular (Wallace et al., 2010; Alfaro-Shigueto et al., 2011). An assessment conducted in Ecuador 2010 based on fisher surveys estimated that more than 13,000 sea turtles die annually as a consequence of bycatch events with small-scale gillnet fisheries in Ecuador (Alfaro-Shigueto et al., 2018).

Bycatch reduction technologies (BRT) have been developed not only to reduce bycatch but also to seek to maintain target catch revenues for fishers (Wang et al., 2013). For instance, the use of light-emitting diode (LED) lights on driftnets, as a visual stimulus, has been shown to be effective at reducing bycatch rates of sea turtles -with no impact on target species- in some countries of the EPO such as Mexico, USA, and Peru (Barkan, 2010; Wang et al., 2010; Ortiz et al., 2016). Building upon this research, the main objective of the present research was to assess the effectiveness of net illumination using violet-colored LED lights at reducing sea turtle bycatch in the Ecuadorian smallscale driftnet fishery. This information could be of relevance for the implementation of the Ecuadorian national strategy to reduce sea turtle bycatch and to support regional efforts for sea turtle populations of conservation concern.

\section{MATERIALS AND METHODS}

\section{Observer onboard program}

An observer monitoring program was implemented from January 2015 to December 2018 on small-scale driftnet fisheries from the fishing ports of Santa Rosa, Puerto Lopez, and Jaramijo (Fig. 1). Observers were trained in biological and fisheries data collection. The information recorded included i) vessel and gear information (e.g., fishing boat, fishing gear, net length, mesh size, numbers of panes and storage capacity), ii) fishing activity information (e.g., set and haul date, set and haul time, geographical position), and iii) target and bycatch data (e.g., species identification, number of individuals captured, and morphometrics).

\section{Experimental design of net illumination trial}

Net trials were conducted onboard 21 driftnet vessels using typical fishing practices. Driftnets ranged in length from 1,000 to $2,000 \mathrm{~m}, 11$ to $17 \mathrm{~m}$ in height, and with a stretched mesh size typically of 4 to 5 inches. Nets comprised multiple panes (between 12 and 16), deployed during the late afternoon (18:00-19:00 h) soaked overnight, and retrieved early the following morning (05:00-07:30 h). The experimental design consisted of pairs of control and illuminated nets deployed per fishing set in which illuminated nets comprised violet-colored LED lights (Centro Power light Model CM-6) attached to the driftnet float line at an interval of 12 to $14 \mathrm{~m}$ (Fig. 2). LED lights were housed in a waterproof plastic case and powered by two AA alkaline batteries.

\section{Data collection}

Observers recorded the composition of captures (target and bycatch species) per set. For the statistical analysis, fish species were grouped into two categories: 'bony fishers' and 'sharks'. The number of target and bycatch 


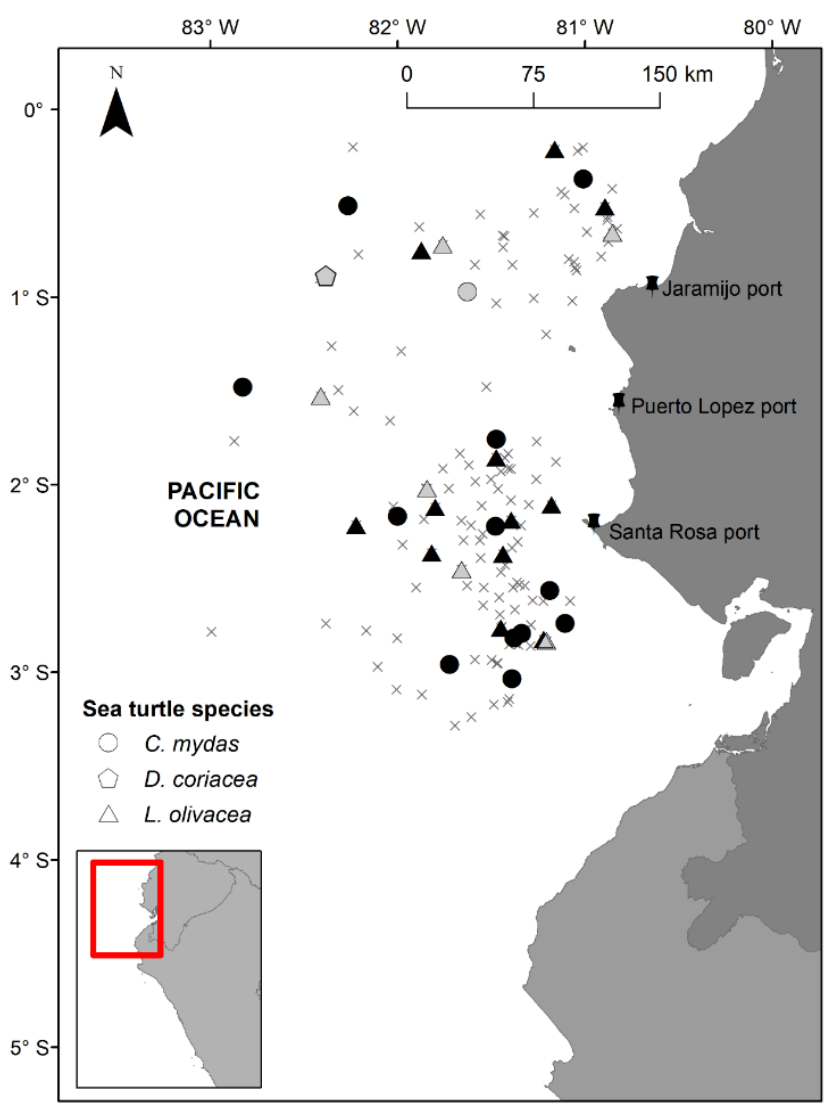

Figure 1. Location of gillnets sets in Ecuador represented by x. Black and grey figures represent sea turtles (Lepidochelys olivacea, Chelonia mydas, Dermochelys coriacea) incidentally captured in control and illuminated nets, respectively.
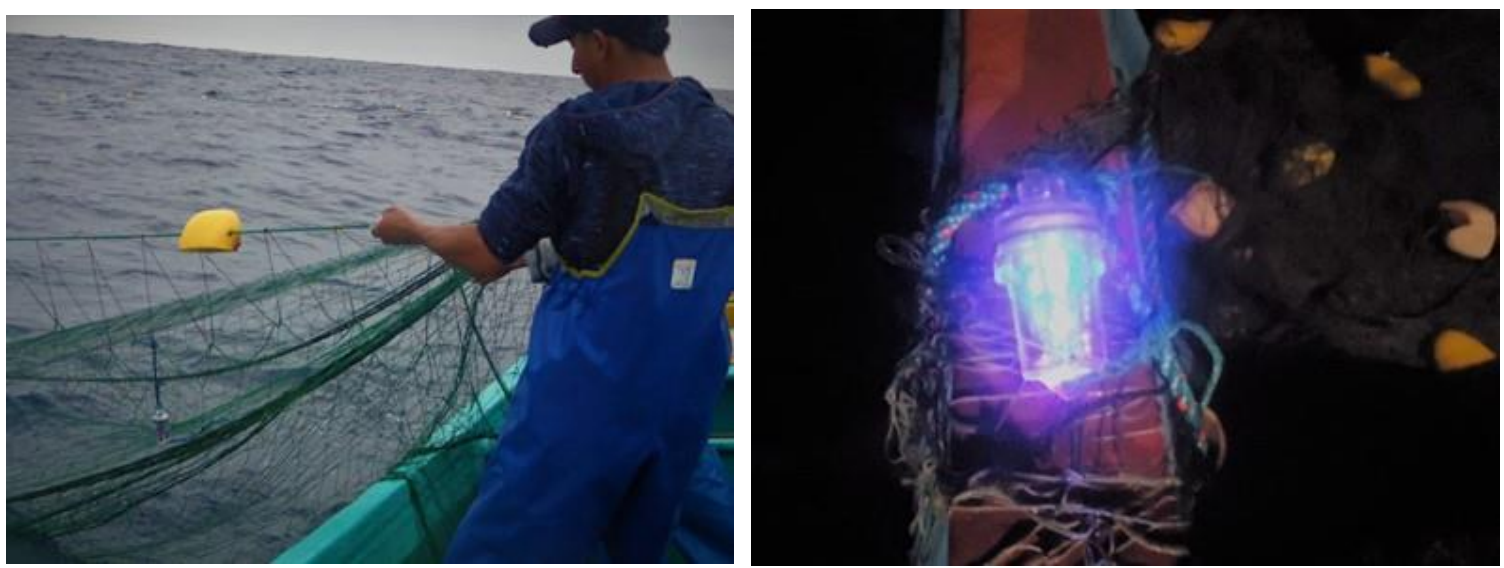

Figure 2. LEDs being recovered during the haul (left), and a LED light attached and activated on the net before the set (right).

specimens captured were used to estimate catch per unit effort (CPUE) and bycatch per unit effort (BPUE) on control and illuminated nets.

Sea turtles captured in illuminated and control net panes were recorded to estimate BPUE. Additionally, entangled turtles were brought onboard for species identification, curved carapace length (CCL) measurements, and were tagged in the front flippers using Inconel tags (Style 681IC, National Band and Tag Company). Based on CCL minimum sizes available in the literature, we inferred size class and classified animals as juveniles or adults. Green turtles (Chelonia 
mydas) with a CCL under $69 \mathrm{~cm}$ (Zarate et al., 2013) and olive ridley turtles (Lepidochelys olivacea) with a CCL under $69.9 \mathrm{~cm}$ (Arias et al., 2015) were considered as putative juveniles. For leatherbacks (Dermochelys coriacea), the CCL for adults was 144 $\mathrm{cm}$, based on measurements of nesting females (Reina et al., 2002). We also recorded the capture position and fate of each captured turtle (release alive or discarded dead). No hawksbill (Eretmochelys imbricata) or loggerhead turtles (Caretta caretta) were reported captured during the study.

\section{Data analysis}

Fishing effort per set was calculated as (net length/1000 $\mathrm{m}) \times($ soak time $/ 24 \mathrm{~h})$. Then, to analyze i) BPUE for sea turtles and ii) CPUE for target species in control and illuminated nets, we fitted separate Generalized Linear Mixed-Effects Models (GLMM) in the statistical modeling program R 3.3.3. (R Core Team, 2017). The models were fitted using the 'glmer' function in the 'Ime4' package (Bates et al., 2015) and the optimizer bobyqa.

For sea turtles, we built a model for all species grouped, as well as separate species-specific models (i.e., olive ridley and green turtles; we did not run a separate model for leatherback since only one individual was captured). For fish species, we built separate models for two species groups: sharks (Selachimorpha) and bony fishes (Osteichthyes). Specifically, given a dependent variable y and a set of $x$ independent covariates, the relationship between them is established by:

$$
y=X \beta+Z u+\varepsilon
$$

The dependent term $(y)$ in our models is a count (number of individuals captured per set) and was modeled with a GLMM with Poisson distribution (or negative binomial, to account for overdispersion) and a $\log$ link function; $X$ is a matrix of the independent covariates or predictor variables. $\beta$ is a vector of the fixed-effects regression coefficient; $Z$ is the matrix for the random effects (the random complement to the fixed $X$ ); $u$ is a vector of the random effects (the random complement to the fixed $\beta$ ); and $\varepsilon$ is a vector of the residuals, that part of $y$ that is not explained by the model.

Full models for (a) sea turtles and (b) target catch included the predictor variable 'treatment' (control or illuminated net) as a fixed effect and the natural logarithm of fishing effort (i.e., $\log$ (Effort)) as an offset term (Table 1) to account for differences in fishing effort between control and illuminated nets and to standardize catch data.
BPUE $\sim$ Treatment $+(\log ($ Effort $))+(1 \mid$ Vessel $/$ TripID $)$

CPUE $\sim$ Treatment $+(\log ($ Effort $))+(1 \mid$ Vessel/ TripID $)$

The variable 'vessel', indicating the name of the vessel, was included as a random effect to account for different fishing practices used on different vessels; the random effect 'TripID' nested in 'vessel' was included as a random effect to account for the changing environmental parameters among seasons, weeks, years and fishing area (Table 1).

The best-fit models with the final terms are summarized in Table 2. The factor treatment was not included in the model for bony fish and sharks, implying that net illumination is not a predictor for the CPUE of these groups.

Models were checked for overdispersion (Zuur et al., 2009) and singularity. If a singularity issue was detected, the random effect structure was simplified by removing the random effect with the lowest variance (Bates et al., 2015) (Table 2).

After establishing the random terms to be included in the model, we performed the information-theoretic (IT) model selection for the fixed effect treatment. The model selection was based on Akaike's information criterion (AIC; Akaike, 1998) and Akaike weights (Burnham \& Anderson, 2002) and used the 'MuMIn' package (Bartoń, 2013), to create a top model set by using a cut-off of $\triangle \mathrm{AIC} \leq 6$, where $\triangle \mathrm{AIC}$ is the difference between the AIC values of the focal model and the AIC best model (Richards, 2005; Richards et al., 2011).

To avoid selecting overly complex models, we selected a model only if it had a $\triangle$ AIC less than the $\triangle \mathrm{AIC}$ of all of its simpler nested models (Richards, 2008). A model is said to be "nested" within another model if it contains a subset of parameters of the latter model but does not include other parameters (e.g., model ' $\mathrm{A}+\mathrm{B}$ ' is nested within ' $\mathrm{A}+\mathrm{B}+\mathrm{C}$ ' but not ' $\mathrm{A}+\mathrm{C}+\mathrm{D}$ '). After this adjustment, the model with the highest adjusted Akaike weight was considered the best-fit model used for the analysis (Burnham \& Anderson, 2002). The amount of variance explained $\left(\mathrm{R}^{2}\right)$ by the best-fit model was calculated using the r.squared GLMM function in the 'MuMIn' package (Bartoń, 2013), and we present lognormal values, both marginal (variance explained by fixed effects only) and conditional (also random effects). The lognormal approximation was chosen because we used error distributions with a logarithmic link.

Expected BPUEs and CPUEs from the GLMM models were determined using the 'predict' function in the 'stats' package. In the results, we present expected 
Table 1. List of predictors (independent variables) included in the generalized linear mixed-effects models.

\begin{tabular}{|c|c|c|c|}
\hline Predictor variable & Fixed/random effect & Type & Description \\
\hline Treatment & Fixed & Categorical & $\begin{array}{l}\text { Control net (i.e., no LEDs applied) or illuminated net } \\
\text { (i.e., LEDs applied) }\end{array}$ \\
\hline Effort & Fixed & Continuous & Fishing effort for control and illuminated net separately \\
\hline TripID & Random & Categorical & Unique code given to each fishing trip \\
\hline Vessel & Random & Categorical & $\begin{array}{l}\text { The name of the vessel on which the experiment was } \\
\text { conducted }\end{array}$ \\
\hline
\end{tabular}

Table 2. Top model sets of generalized linear mixed-effect models (GLMM) for sea turtle and target groups. Within the top model sets, models used for predictions (the best-fit models) are highlighted in grey. Group: species group whose data were analyzed with the model. Family: error distribution used for the model. Response: the dependent variable, i.e., estimated bycatch per unit effort (BPUE) for sea turtles and catch per unit effort (CPUE) for target catch. Fixed effects: the explanatory variables included in the model. Random effects: the random effects included in the model. AIC: Akaike's Information Criterion. $\triangle \mathrm{AIC}$ : difference in AIC relative to the model with the lowest AIC. Weight: Akaike's weight. Adj. weight: adjusted weights calculated after excluding nested models. $\mathrm{R}^{2}$ : marginal $\mathrm{R}^{2}$, i.e., amount of variance explained by the model including fixed effects only. $\mathrm{R}^{2}$ : conditional $\mathrm{R}^{2}$, i.e., amount of variance explained by the model including fixed and random effects.

\begin{tabular}{|c|c|c|c|c|c|c|c|c|c|c|}
\hline Group & Family & Response & Fixed effects & Random effects & AIC & $\Delta \mathrm{AIC}$ & Weight & $\begin{array}{l}\text { Adj. } \\
\text { weight }\end{array}$ & $\mathrm{R}_{\mathrm{m}}^{2}$ & $\mathrm{R}_{\mathrm{c}}^{2}$ \\
\hline \multirow[t]{2}{*}{$\begin{array}{l}\text { All } \\
\text { turtles }\end{array}$} & Poisson & BPUE & $\begin{array}{l}\sim \text { Treatment }+ \\
\text { offset }(\log (\text { Effort }))\end{array}$ & (1|Vessel) & 203.26 & 0.00 & 0.92 & 0.92 & 0.10 & 0.11 \\
\hline & & & $\sim \operatorname{offset}(\log ($ Effort $))$ & (1|Vessel) & 208.16 & 4.89 & 0.08 & 0.08 & - & - \\
\hline $\begin{array}{l}\text { Green } \\
\text { turtles }\end{array}$ & Poisson & BPUE & $\begin{array}{l}\sim \text { Treatment }+ \\
\text { offset(log(Effort)) }\end{array}$ & (1|Vessel) & 98.98 & 0.00 & 1.00 & 1.00 & 0.28 & 0.37 \\
\hline \multirow{2}{*}{$\begin{array}{l}\text { Olive } \\
\text { ridley } \\
\text { turtles }\end{array}$} & Poisson & BPUE & $\sim \operatorname{offset}(\log ($ Effort $))$ & (1|TripID) & 141.55 & 0.00 & 0.57 & 1.00 & 0.00 & 0.18 \\
\hline & & & $\begin{array}{l}\sim \text { Treatment }+ \\
\text { offset(log(Effort)) }\end{array}$ & (1|TripID) & 142.08 & 0.53 & 0.43 & - & - & \\
\hline \multirow[t]{2}{*}{$\begin{array}{l}\text { Bony } \\
\text { fish }\end{array}$} & $\begin{array}{l}\text { Negative } \\
\text { binomial }\end{array}$ & CPUE & $\sim \operatorname{offset}(\log ($ Effort $))$ & (1|Vessel/TripID) & 1958.68 & 0.00 & 0.63 & 1.00 & 0.00 & 0.72 \\
\hline & & & $\begin{array}{l}\sim \text { Treatment }+ \\
\text { offset(log(Effort) }\end{array}$ & (1|Vessel/TripID) & 1959.76 & 1.08 & 0.37 & - & - & - \\
\hline \multirow[t]{2}{*}{ Sharks } & Poisson & CPUE & $\sim \operatorname{offset}(\log ($ Effort $))$ & (1|Vessel/TripID) & 315.74 & 0.00 & 0.73 & 1.00 & 0.00 & 0.70 \\
\hline & & & $\begin{array}{l}\sim \text { Treatment }+ \\
\text { offset }(\log (\text { Effort }))\end{array}$ & (1|Vessel/TripID) & 317.72 & 1.98 & 0.27 & - & - & - \\
\hline
\end{tabular}

CPUEs and BPUEs, i.e., the expected number of individuals captured when fishing effort $=1$, if the model includes 'treatment' as a predictor.

\section{RESULTS}

\section{Fishing effort}

A total of 146 experimental sets (illuminated and control) were completed. As driftnets consisted of a single long net, we sought for each fishing set to have equivalent portions of the net illuminated as control (non-illuminated). Control nets length averaged $0.89 \pm$ $0.15 \mathrm{~km}$ (mean \pm standard error, SE), while illuminated nets averaged $0.81 \pm 0.05 \mathrm{~km}$. For set duration (soak time), control and illuminated nets averaged $11.74 \pm$
$1.67 \mathrm{~h}$. Fishing effort calculated for control nets averaged $0.44 \pm 0.10(\mathrm{~km} \times 24 \mathrm{~h})$, and for illuminated nets averaged $0.39 \pm 0.06(\mathrm{~km} \times 24 \mathrm{~h})$.

\section{Sea turtle bycatch}

During the experiment, 32 sea turtles were incidentally captured, of which $56.3 \%$ were olive ridley (Lepidochelys olivacea), $40.6 \%$ green (Chelonia mydas), and $3.1 \%$ (one individual) was a leatherback (Dermochelys coriacea) turtle (Table 3).

Mean CCL for olive ridley turtles was $57.7 \pm 3.6 \mathrm{~cm}$ (mean \pm SE) (range: 20 to $73 \mathrm{~cm}$ ) and $44.4 \pm 4.2 \mathrm{~cm}$ (mean \pm SE) for green turtles (range: 43 to $77 \mathrm{~cm}$ ). All green turtles and the leatherback incidentally captured were classified as juveniles; $72 \%$ of olive ridleys were 
Table 3. The number of individuals captured in control and illuminated nets by species. Effort $\left(\mathrm{km} \mathrm{d}^{-1}\right)$ is the total fishing effort. CM: Chelonia mydas; LO: Lepidochelys olivacea; DC: Dermochelys coriacea. BF: bony fish; SH: sharks.

\begin{tabular}{|c|c|c|c|c|c|c|}
\hline \multirow{2}{*}{ Treatment } & \multirow{2}{*}{$\frac{\text { Effort }}{\left(\mathrm{km} \mathrm{d}^{-1}\right)}$} & \multicolumn{3}{|c|}{ Sea turtles } & \multicolumn{2}{|c|}{ Fish species } \\
\hline & & $\mathrm{CM}$ & LO & $\mathrm{DC}$ & $\mathrm{BF}$ & SH \\
\hline Control & 63.6 & 12 & 12 & 0 & 2082 & 39 \\
\hline Illuminated & 57.6 & 1 & 6 & 1 & 1937 & 35 \\
\hline
\end{tabular}

Table 4. CCL measurements ( $\mathrm{cm}$ ) and fate by sea turtle species (olive ridley: Lepidochelys olivacea, green: Chelonia mydas, leatherback: Dermochelys coriacea) incidentally captured in control and illuminated nets. SE: standard error.

\begin{tabular}{llccc}
\hline \multirow{2}{*}{ Treatment } & \multirow{2}{*}{ Sea turtle species } & CCL $(\mathrm{cm})$ & \multicolumn{2}{c}{ Fate \% $(\mathrm{n})$} \\
\cline { 3 - 5 } & & Mean \pm SE & Released alive & Discarded dead \\
\hline Control & Olive ridley & $57.7 \pm 3.6$ & $100(12)$ & 0 \\
& Green & $44.4 \pm 4.2$ & $83(10)$ & $17(2)$ \\
& Leatherback & - & 0 & 0 \\
\hline Illuminated & Olive ridley & $52.8 \pm 7.1$ & $67(4)$ & $33(2)$ \\
& Green & 56 & $100(1)$ & 0 \\
& Leatherback & 128 & $100(1)$ & 0 \\
\hline
\end{tabular}

adults. Eighty-eight percent of the turtles captured were released alive (Table 4). Four turtles were recovered dead from the net, likely from drowning.

Regarding data analysis, the best-fit models with the final terms are summarized in Table 2. The factor 'treatment' was retained in the model for all turtle species combined and for green turtles individually. The GLMM indicates that the expected BPUE is lower in illuminated nets than in control nets for all sea turtle species and green turtles only, with reductions in BPUE of 62.2 and $93.3 \%$, respectively (Fig. 3). For all turtle species, the expected bycatch BPUE is $0.37 \mathrm{~km} \times 24 \mathrm{~h}$ in control nets compared to $0.14 \mathrm{~km} \times 24 \mathrm{~h}$ in illuminated nets. For green turtles only, the expected BPUE is $0.15 \mathrm{~km} \times 24 \mathrm{~h}$ in control nets as compared to 0.01 $\mathrm{km} \times 24 \mathrm{~h}$ in illuminated nets (Fig. 3). For olive ridley turtles, 'treatment' was not included in the model, implying that the net illumination is not a predictor for the BPUE of this species.

\section{Fish catch}

A total of 4019 bony fishes and 74 sharks were recorded (Table 3). Among bony fishes captured, it was possible to identify species from the genus Thunnus and other species such as skipjack tuna (Katsuwonus pelamis) and mahi-mahi (Coryphaena hippurus). Shark species identified include thresher sharks (Alopias spp.), hammerhead sharks (Sphyrna spp.), and other species such as crocodile sharks (Pseudocarcharias kamoharai), blue sharks (Prionace glauca) and mako sharks (Isurus oxyrinchus).
The best-fit models with the final terms are summarized in Table 2. The factor Treatment was not included in the model for bony fish and sharks, implying that net illumination is not a predictor for the CPUE of these groups.

\section{DISCUSSION}

\section{Effect on turtle bycatch}

Our study shows that net illumination using violetcolored LEDs reduced sea turtle bycatch by small-scale driftnet vessels by $62.2 \%$, which corroborates findings of similar studies in the EPO (Wang et al., 2013; Ortiz et al., 2016). Also, our results yielded novel, speciesspecific findings regarding the effects of net illumination on sea turtle bycatch. We assessed for species-level effects and found that net illumination reduced green turtle Chelonia mydas bycatch, a result similar to that of Wang et al. (2013). However, net illumination did not show the same effect on the bycatch of olive ridley turtles. This study is the first to assess the impact on olive ridley turtles Lepidochelys olivacea as other studies (using green LEDs) reported captures of only single individuals (Ortiz et al., 2016; Kakai, 2019).

The wavelength (100-400 $\mathrm{nm}$ ) emitted by the LEDs used in this study is within the visual range of both the green and olive ridley turtle (Witherington, 1992). Nevertheless, as sea turtle response to wavelengths is associated with light intensity and varies among species (Cruz et al., 2018), a better understanding of the light intensity effect on wavelength sensitivity could help to 


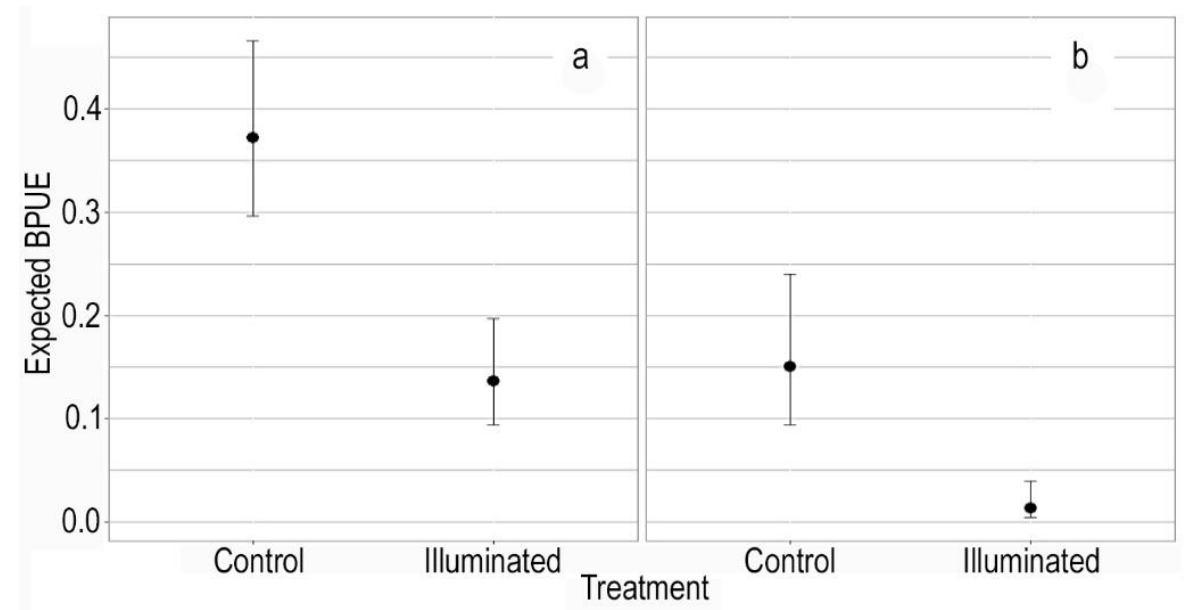

Figure 3. Expected BPUEs (individuals/km/day) in control and illuminated nets for a) all turtle species (Lepidochelys olivacea, Chelonia mydas, Dermochelys coriacea) and b) green turtles C. mydas only. Error bars are standard errors.

understand differences at a species level found by the model. In case sensitivity to light intensity is playing a crucial role in bycatch reduction effectiveness for individual species, an increase in the number of lights deployed per net panel could be an alternative for having a detectable effect of lights on olive ridley bycatch (Wang et al., 2010). In addition to light intensity, it is important to consider that environmental conditions (i.e., water visibility, sea surface temperature, lunar light) may be influencing net illumination efficiency as has been considered in previous studies (Ortiz et al., 2016; Virgili et al., 2018).

Previous studies suggest that sea turtles inhabiting southeastern Pacific waters belong to breeding areas such as Galapagos Islands, Mexico, Costa Rica, but also from the western Pacific (Velez-Zuazo \& Kelez, 2010; Alfaro-Shigueto et al., 2011; Dutton et al., 2013; Alvarez-Varas et al., 2017). Our study shows that most turtle bycatch events were of putative juveniles, most likely individuals from the rookeries mentioned above that are using Ecuador's coastal waters as feeding grounds. Given the conservation status of some of these turtle populations (e.g., leatherbacks turtles Dermochelys coriacea of the EPO) and even though $88 \%$ of sea turtles in our study were released alive, these interactions may still represent a risk for these EPO populations due to the unknown levels of postrelease mortality. Thus, even though net illumination with UV LEDs may represent a promising BRT, its implementation should be complemented with fisher training on sea turtle safe-handling and release techniques.

\section{Effect on fish catch}

Net illumination did not affect the capture efficiency of commercial species (bony fishes and sharks), a finding that is in line with other recent studies of net illumination (Ortiz et al., 2016; Virgili et al., 2018). It is important to consider, however, that we assessed target catch in terms of the number of individuals but did not assess the effect on specimen size or weight, which are also important metrics in terms of target catch economic value. Previous studies have shown that neither catch size, catch composition, or catch value is affected by net illumination (Wang et al., 2013; Virgili et al., 2018). However, future assessments should include the effect on target catch weight or size as any economic loss would be part of the cost associated with the implementation of net illumination.

It is also worth mentioning that apart from the violet LEDs tested here, a study conducted in Peru showed that green LEDs also reduced green turtle bycatch in commercial gillnet fisheries without affecting target catch rates (Ortiz et al., 2016). Bycatch in that study was exclusive to green turtles, however, making it clear that net illumination using green LED lights (as an alternative to violet LED lights) could also be tested in the Ecuadorian commercial gillnet fisheries.

It is encouraging that multiple studies have now shown that net illumination reduces turtle bycatch with no impact on target catch; however, local implementation may still be challenging due to the associated costs. We encourage the development of estimations of the costs associated with the implementation of net illumination as a BRT and how it may affect fishers' incomes. However, net illumination also has the potential to alleviate fishing gear damage associated with bycatch events (Panagopoulou et al., 2017). In this regard, it will be important to analyze the socioeconomic factors that may affect the implementation of net illumination in Ecuador as each country may have particular issues and concerns. 
Our study supports net illumination as a BRT for green turtles but provides evidence that its efficiency may vary between sea turtle species. Continuation of the testing of this BRT with different fishing gear types is recommended to more fully understand the efficacy of net illumination on bycatch reduction for different sea turtle species as well as on other taxa. Further testing will also provide the data necessary for more widespread implementation and its possible inclusion as part of a national strategy focusing on bycatch reduction.

\section{ACKNOWLEDGMENTS}

We thank the fishermen from Santa Rosa, Puerto Lopez, and Jaramijo for their support during the study. Staff from Ecuador Mundo Ecológico and Pro Delphinus supported this study in many ways. Funds were provided by the National Fish and Wildlife Foundation and the Darwin Initiative through the University of Exeter, UK.

\section{REFERENCES}

Alava, J.J., Lindop, A. \& Jacquet, J. 2015. Marine fisheries catch reconstructions for continental Ecuador, 1950-2010. Fisheries Centre, University of British Columbia, Working Paper Series, 34:, 1-25.

Alava, J.J., Tatar, B., Barragán, M.J., Castro, C., Rosero, P., Denkinger, J., et al. 2019. Mitigating cetacean bycatch in coastal Ecuador: governance challenges for small-scale fisheries. Marine Policy, 110: 1-9. doi: 10.1016/j.marpol.2017.05.025

Alfaro-Shigueto, J., Mangel, J.C., Bernedo, F., Dutton, P.H., Seminoff, J.A. \& Godley, B.J. 2011. Small-scale fisheries of Peru: a major sink for marine turtles in the Pacific. Journal of Applied Ecology, 48(6): 14321440. doi: 10.1111/j.1365-2664.2011.02040.x

Alfaro-Shigueto, J., Mangel, J.C., Darquea, J., Donoso, M., Baquero, A., Doherty, P.D. \& Godley, B.J. 2018. Untangling the impacts of nets in the southeastern Pacific: rapid assessment of marine turtle bycatch to set conservation priorities in small-scale fisheries. Fisheries Research, 206: 185-192. doi: 10.1016/j. fishres.2018.04.013

Alvarez-Varas, R., Contardo, J., Heidemeyer, M., Forero, L., Brito, B., Cortes, V., et al. 2017. Ecology, health, and genetic characterization of the southernmost green turtle (Chelonia mydas) aggregation in the eastern Pacific: implications for local conservation strategies. Latin American Journal of Aquatic Research, 45(3): 540-554. doi: 10.3856/vol45-issue3-fulltext-4
Anderson, O.R.J., Small, C.J., Croxall, J.P. \& Dunn, E.K. 2011. Global seabird bycatch in longline fisheries. Endangered Species Research, 14: 91-106. doi: 10.3354/esr00347

Arias, O.B., Bonilla, L.B., Salazar, A.B. \& Delgado, A.V. 2015. Características de la anidación de Lepidochelys olivacea (Testudinata: Cheloniidae) entre el 2010 y 2012 en Playa Tortuga Ojochal de Osa, Puntarenas, Costa Rica. Revista de Biología Tropical, 63(1): 339349. doi: $10.15517 /$ rbt.v63i1.23113

Attwood, C.G., Petersen, S.L. \& Kerwath, S.E. 2011. Bycatch in South Africa's offshore trawl fishery as determined from observer records. ICES Journal of Marine Science, 68(10): 2163-2174. doi: 10.1093/ icesjms/fsr 162

Barkan, J. 2010. A plan to reduce sea turtle bycatch in small-scale gillnet fisheries using illuminated nets. Center for Marine Biodiversity and Conservation, University of California, San Diego.

Bartoń, K. 2013. MuMIn: multi-model inference. R Package Version 1.10.0, 75 pp.

Bates, D., Kliegl, R., Vasishth, S. \& Baayen, H. 2015. Parsimonious mixed models. Cornell University, Ithaca.

Burnham, K. \& Anderson, D. 2002. Model selection and multi-model inference: a practical information-theoretic approach. Springer, New York.

Chaves, J.A., Peña, M., Valdés-Uribe, J.A., Muñoz-Pérez, J.P., Vallejo, F., Heidemeyer, M. \& Torres-Carvajal, O. 2017. Connectivity, population structure, and conservation of Ecuadorian green sea turtles. Endangered Species Research, 32: 251-264.

Cruz, L.M., Shillinger, G.L., Robinson, N.J., Tomillo, P.S. \& Paladino, F.V. 2018. Effect of light intensity and wavelength on the in-water orientation of olive ridley turtle hatchlings. Journal of Experimental Marine Biology and Ecology, 505: 52-56. doi: 10.1016/j. jembe. 2018.05.002

Dutton, P.H., Roden, S.E., Stewart, K.R., Lacasella, E., Livingstone, S.R., Tiwari, M. \& Phil, R. 2013. Population stock structure of leatherback turtles (Dermochelys coriacea) in the Atlantic revealed using mtDNA and microsatellite markers. Conservation Genetics, 14: 625-636. doi: 10.1007/s10592-013-0456-0

Gaos, A.R., Liles, M.J., Gadea, V., Peña de Niz, A., Vallejo, F., Miranda, C., et al. 2017. Living on the edge: hawksbill turtle nesting and conservation along the eastern Pacific Rim. Latin American Journal of Aquatic Research, 45(3): 572-584.

Heppell, S.S., Caswell, H. \& Crowder, L.B. 2000. Life history and elasticity patterns: Perturbation analysis for species with minimal demographic data. Ecology, 81(3): 654-665. 
Kakai, T.M. 2019. Assessing the effectiveness of LED lights for the reduction of sea turtle bycatch in an artisanal gillnet fishery-a case study from the north coast of Kenya. Western Indian Ocean Journal of Marine Science, 18(2): 3-44.

Kelleher, K. 2005. Discards in the world's marine fisheries: an update. FAO, Rome.

Lewison, R.L., Crowder, L.B., Read, A.J. \& Freeman, S.A. 2004. Understanding impacts of fisheries bycatch on marine megafauna. Trends in Ecology and Evolution, 19(11): 598-604. doi: 10.1016/j.tree.2004. 09.004

Lewison, R.L., Crowder, L.B., Wallace, B.P., Moore, J.E., Cox, T., Zydelis, R., et al. (2014). Global patterns of marine mammal, seabird, and sea turtle bycatch reveal taxa-specific and cumulative megafauna hotspots. Proceedings of the National Academy of Sciences, 111(14): 5271-5276. doi: 10.1073/pnas.1318960111

Ministerio del Ambiente (MAE). 2014. Plan nacional para la conservación de las tortugas marinas. MAE, Guayaquil. [http://conservation.org.ec/wp-content/uploads/2014/12/ Plan-Nacional-Tortugas-COMPLETO-PdF.pdf]. Reviewed: July 12, 2019.

Mangel, J.C., Alfaro-shigueto, J., Waerebeek, K. Van, Cáceres, C., Bearhop, S., Witt, M.J. \& Godley, B.J. 2010. Small cetacean captures in Peruvian artisanal fisheries: high despite protective legislation. Biological Conservation, 143(1): 136-143. doi: 10.1016/ j.biocon.2009.09.017

Martínez-Ortiz, J., Aires-Da-Silva, A.M., Lennert-Cody, C.E. \& Maunderxs, M.N. 2015. The Ecuadorian artisanal fishery for large pelagics: species composition and spatio-temporal dynamics. Plos One, 10(8): 1-29. doi: 10.1371/journal.pone.0135136

Montero, J.T., Martinez-Rincon, R.O., Heppell, S.S., Hall, M. \& Ewal, M. 2016. Characterizing environmental and spatial variables associated with the incidental catch of olive ridley (Lepidochelys olivacea) in the eastern Tropical Pacific purse-seine fishery. Fisheries Oceanography, 25(1): 1-14. doi: 10.1111/fog. 12130

Ortiz, N., Mangel, J.C., Wang, J., Alfaro-Shigueto, J., Pingo, S., Jimenez, A. \& Godley, B.J. 2016. Reducing green turtle bycatch in small-scale fisheries using illuminated gillnets: the cost of saving a sea turtle. Marine Ecology Progress Series, 545: 251-259. doi: 10.3354/meps11610

Panagopoulou, A., Meletis, Z.A., Margaritoulis, D., Spotila, J.R., Virgili, M., Vasapollo, C. \& Dutton, P.H. 2017. Small-scale fisheries of Peru: a major sink for marine turtles in the Pacific. NOAA Technical Memorandum NMFS-SEFSC, 4: 1432-1440. doi: 10.1111/j. 1365-2664.2011.02040
Peña-Mosquera, M.P., Baquero-Gallegos, A.B., MuñozPérez, J.M., Puebla-Jiménez, F., Álvarez, V. \& Chalen-Noroña, X. 2009. El Parque Nacional Machalilla zona crítica de anidación de tortuga carey (Eretmochelys imbricata) y verde (Chelonia mydas) en el Ecuador y el Pacífico Oriental. Temporada 20072009. Fundación Equilibrio Azul, Quito.

R Core Team. 2019. R: A language and environment for statistical computing. R Foundation for Statistical Computing. [http://www.R-project.org]. Reviewed: June 10, 2019.

Reina, R.D., Mayor, P.A., Spotila, J.R., Piedra, R. \& Paladino, F.V. 2002. Nesting ecology of the leatherback turtle, Dermochelys coriacea, at Parque Nacional Marino las Baulas, Costa Rica: 1988-1989 to 19992000. Copeia, (3): 653-664. doi: 10.1643/00458511(2002)002[0653:NEOTLT]2.0.CO;2

Richards, S.A. 2005. Testing ecological theory using the information-theoretic approach: examples and cautionary results. Ecology, 86(10): 2805-281.

Richards, S.A. 2008. Dealing with overdispersed count data in applied ecology. Journal of Applied Ecology, 45(1): 218-227. doi: 10.1111/j.1365-2664.2007.013 77. $\mathrm{x}$

Richards, S.A., Whittingham, M.J. \& Stephens, P.A. 2011. Model selection and model averaging in behavioral ecology: the utility of the IT-AIC framework. Behavioral Ecology and Sociobiology, 65(1): 77-89. doi: 10.1007/s00265-010-1035-8

Soykan, C.U., Moore, J.E., Ždelis, R., Crowder, L.B., Safina, C. \& Lewison, R.L. 2008. Why study bycatch? An introduction to the theme section on fisheries bycatch. Endangered Species Research, 5(2-3): 91102. doi: $10.3354 /$ esr00175

Thiel, M., Luna-Jorquera, G., Álvarez-Varas, R., Gallardo, C., Hinojosa, I.A., Luna, N., et al. 2018. Impacts of marine plastic pollution from continental coasts to subtropical gyres-fish, seabirds, and other vertebrates in the SE Pacific. Frontiers in Marine Science, 5: 238. doi: 10.3389/fmars.2018.00238

Velez-Zuazo, X. \& Kelez, S. 2010. Multiyear analysis of sea turtle bycatch by Peruvian longline fisheries: a genetic perspective. Proceedings of the 30th Annual Symposiumon Sea Turtle Biology and Conservation, 24-30 April 2010, Goa, India. doi: 10.1137/1.9781 611975482

Virgili, M., Vasapollo, C. \& Lucchetti, A. 2018. Can ultraviolet illumination reduce sea turtle bycatch in Mediterranean set net fisheries? Fisheries Research, 199: 1-7. doi: 10.1016/j.fishres.2017.11.012

Wallace, B.P., Lewison, R.L., Mcdonald, S.L., Mcdonald, R.K., Kot, C.Y., Kelez, S. \& Crowder, L.B. 2010. 
Global patterns of marine turtle Conservation Letters, 3(3): 131-142. doi: 10.1111/j.1755-263X.2010.00 105.x

Wang, J., Barkan, J., Fisler, S., Godinez-Reyes, C. \& Swimmer, Y. 2013. Developing ultraviolet illumination of gillnets as a method to reduce sea turtle bycatch. Biology Letters, 9(5). doi: 10.1098/rsbl.2013. 0383

Wang, J.H., Fisler, S. \& Swimmer, Y. 2010. Developing visual deterrents to reduce sea turtle bycatch in gillnet fisheries. Marine Ecology Progress Series, 408: 241250. doi: $10.3354 /$ meps08577

Received: 9 September 2019; Accepted: 10 March 2020
Witherington, B.E. 1992. Sea-finding behavior and the use of photic orientation cues by hatchlings sea turtles. The University of Florida, Florida.

Zarate, P., Bjorndal, K.A., Parra, M., Dutton, P.H., Seminoff, J.A. \& Bolten, A.B. 2013. Hatching and emergence success in green turtle Chelonia mydas nests in the Galápagos Islands. Aquatic Biology, 19(3): 217-229. doi: 10.3354/ab00534

Zuur, A., Ieno, E.N., Walker, N., Saveliev, A.A. \& Smith, G.M. 2009. Mixed-effects models and extensions in ecology with R. Springer Science \& Business Media, Berlin. 